\title{
XI. On the condensation and the critical phenomena of mixtures of ethane and nitrous oxide
}

\author{
Dr. Kuenen
}

To cite this article: Dr. Kuenen (1895) XI. On the condensation and the critical phenomena of mixtures of ethane and nitrous oxide , Philosophical Magazine Series 5, 40:243, 173-194, DOI: $10.1080 / 14786449508620759$

To link to this article: http://dx.doi.org/10.1080/14786449508620759

曲 Published online: 08 May 2009.

Submit your article to this journal $[\pi$

Џll Article views: 3

Q View related articles $\sqsubset$ 
XI. On the Condensation and the Critical Phenomena of Mixtures of Ethane and Nitrous Oxide. By Dr. KuEnen*.

1. REFORE relating the results arrived at in this investigation I shall have to give a short account of the course of thought which led to the choice of the subject.

My experiments on the conduct of mixtures $\dagger$ are based upon the theory of Prof. van der Waals $\ddagger$. Van der Waals "describes" the properties of mixtures by means of an isothermal surface, the coordinates of which are the composition of the mixture $x(0<x<1)$, the volume $v$, and the free energy $\psi(\psi=\epsilon-t \eta ; \epsilon=$ energy, $\eta=$ entropy, $t=$ temperature $)$. On this surface there appear plaits $\S$, which determine the coexistence of two or more phases. Those points of these plaits which have a common tangent plane represent the phases which may coexist at the temperature for which the surface is constructed, and at a pressure indicated by the slope of the tangent plane $\left(p=-\frac{\partial \psi}{\partial v}\right)$. The clouble curves traced out by rolling the tangent planes orer the plaits are the so-called connodal curves. It may happen that the plaits terminate on the surface itself $(i, e$. between the planes for which $x=0$ and $x=1$ ). In that case the coexisting phases approach each other and at last coincide in a so-called plaitpoint. In studying the plaits on the surface, one may use the projection upon the $x-v$ plane. This projection consists of the $x$-axis between $x=0$ and $x=1$, the two $x$-axes for $x=0$ and $x=1$, the connodal curves with or without the plaitpoints. The points of the connodal curves belonging together may be joined by straight lines. The ratio of the parts into which these lines are divided by a line perpendicular to the $x$-axis, say for $x=x_{1}$, represents the ratio of the quantities of the two phases which will be formed when the mixture $x_{1}$ is taken at the pressure at which the two phases may coexist. Keeping this in view, it is easy to derive the condensation and critical phenomena of a mixture.

2. We shall only discuss the very simple case here, that

* Communicated by the Physical Society : read May 24, 1895.

+ Kuenen, Archives Néerl. xxvi.pp. 354-422; Zeitschr. phys. Chemie, xi. pp. 38-48; Verhand. Kon. Akad. Amstesdam, passim; Communications from the Labor. of Physics, Leiden, Nos. 4, 7, 13.

I Van der Waals, Archives Néerl. xxiv. pp. 1-56; Zeitschr. phys. Chemie, v. pp. 133-173.

$\S$ For the nomenclature used in this treatise, $c f$. Korteweg, Wien. Ber. xcriii. pp. 1154-1191; Archives Néerl. xxiv. pp. 57-98. 
there is only one plait on the surface, the vapour-liquid plait, which determines the coexistence of a vapour-phase and a liquid-phase. The plait, roughly speaking, has the direction of the $x$-axis ; its plaitpoint, which will make its appearance if only we raise the temperature to a sufficient height, need not coincide with the end of the plait, i.e. with that point of the connodal enrve which is nearest to one of the $\psi v$ planes (in the projection $=v$-axis) ${ }_{-1}$ The latter point was called critical point of contact*. Now in deriving the critical phenomena two cases have to be distinguished depending on the relative position of these two points, which we shall call $\mathrm{P}$ and $\mathrm{R}$. Either $\mathrm{P}$ is situated nearer to the $\psi \cdot x$ plane ( $x$-axis) or this is the case with $R$.

3 . In the first case the condensation of a mixture has the following character. Below a detinite temperature (plaitpointtemperature $=T_{P}$ ), different for every mixture, the quantity of the denser phase increases regularly during compression; the pressure rises, and both the composition and the volume of both phases change continuously. Above anotber temperature (temperature of the critical point of contact $=$ critical temperature $=\mathrm{T}_{\mathbf{R}}$ ) there is no condensation possible. At temperatures ranging between $T_{P}$ and $T_{n}$ the condensation will have the following character :-With compression the quantity of the appearing liquid first increases, reaches a maximum value, and after that decreases till it disappears. This was called retrograde condensation of the first kind (r.c. I.) $\dagger$. The nearer we get to the plaitpoint-temperature the larger becomes the quantity of the liquid and the smaller the difference between the phases, apparent from a less distinct liquid surface between the phases. A mixture, therefore, has a critical region instead of one critical point, lying between two critical temperatures.

4. The phenomena predicted in this manner were then observed by me in mixtures of carbonic acid and methyl chloride $\ddagger$, and afterwards of carbonic acid and air $\S$. The deviation from what had been observed by former experimenters, viz., the flattening and disappearing of the liquid suriace throughout the critical region without retrograde

* Kuenen, Archives Néerl. xxvi. p. 379; Communications from the Lab. of Physics, Leiden, No. 4, pp. 7 sqq.; Zeitschrift phys. Chemie, xi. p. 44.

† Kuenen, Archives Néerl. xxvi. pp. 378-379; Commun. No. 4 ; Zeitschr. phys. Chemie, xi. p. 44.

* Kuenen, Archives Néerl. xxvi. pp. 382-385; Commun. No. 4; Zeitschr: phys. Chemie, xi. p. 47.

$\$$ Commun. No. 7, p. 6 . 
condensation, was explained by retardation*, which was annihilated in my experiments for the first time by means of a small iron stirring-rod within the tubes, which was moved by an electromagnet outside the tubes.

5. If $\mathrm{P}$ lies on the other side of $\mathrm{R}$ there are again two definite critical temperatures, $T_{P}$ and $T_{R}$, for every mixture ; but the process of condensation between those two will be different from what it was in the first ease. By compression a new phase appears of a larger volume this time, $i$ e e. a vapour-phase, which begins by increasing, then reaches a maximum, and then again diminishes and disappears. This was called retrograde condensation of the second lind (r.c. II.) $\neq$. Near the plaitpoint-temperature $\mathrm{T}_{\mathrm{P}}$ the liquid will be very flat and indistinct, and more so at the begiming than near the end of the condensation. Below ' $T_{P}$ the condensation is normal.

6. This second case has never been realized till now. I have been considering whether it might be, and the choice of the subject of this paper is the outcome of my reasoning. In explaining this 1 shall use a different graphical representation, namely the $p-t$ figure. In a recent paper $\$$ I have deduced the general features of the $p-t$ curves in the problem before us from van der Waals's theory. The figure obtained consists of (1) the two vapour-pressure curres of the component substances; (2) the border-curves $\|$ for the mixtures ( $x=$ constant) having the form of loops ; (3) the plaitpointcurve, being the envelope of the border-curves and connecting the critical points of the two substances. The point of contact between a border-curve and the plaitpoint-curve corresponds to the plaitpoint $\mathrm{P}$ of van der Waals's surface; the critical point of contact $R$ is the point in which the bordercurve has a tangent parallel to the $p$-axis. When going along the border-curve, starting from its lower branch, we may either first reach R or P. These two cases correspond to the

* Kuenen, Archives Néerl. xxvi. pp. 376-377, 380-382; Commun. No. 4 ; Zeitschr. phys. Chemie, xi. p. 4h.

$\dagger$ In order to make the volumes in our figures decide about the situation of the phases above each other, we should take the volume of the unit of weight as the unit of volume. In doing so a phase of larger volume is a lighter phase at the same time, and will therefore appear in the upper part of the tube.

† Kuenen, Archives Néerl. xxvi. pp. 388-389; Zeitschr.phys. Chemie, xi. p. 45.

§ Kuenen, Kon. Akad. Amsterdam, 29 Sept. 1894, pp. 90-99; 'Communications,' \&c. No. 13.

if A border-curve for a mixture reprezents the conditions $(l, t)$ in which it may coexist with a second phase. 
two cases mentioned above. If $\mathrm{P}$ is situated beyond $\mathrm{R}$ we have r.c. I. (figs. 8, 9); if $\mathrm{R}$ lies beyond $\mathrm{P}$ we have r.c. II. (fig. 10). Keeping in view the connexion between bordercurve and plaitpoint-curve, the question whether the second case can be realized comes to the same as whether the plaitpoint-curve or a part of it may rise, while the border-curves are situated on its left side (fig. 10). Now it appears that there are different cases in which such a situation must occur. If the critical points of some of the mixtures lie outside the critical temperatures of the two substances, a part of the plaitpoint-curve will answer to the above postulate. But this is not a necessary condition. If the substance of the higher critical temperature has at the same time larger vapourpressures than the substance of the lower critical temperature, the plaitpointwcurve will have the same property. This case is represented in fig. $1 . R$ lies beyond $P$. Between the

Fig. 1.

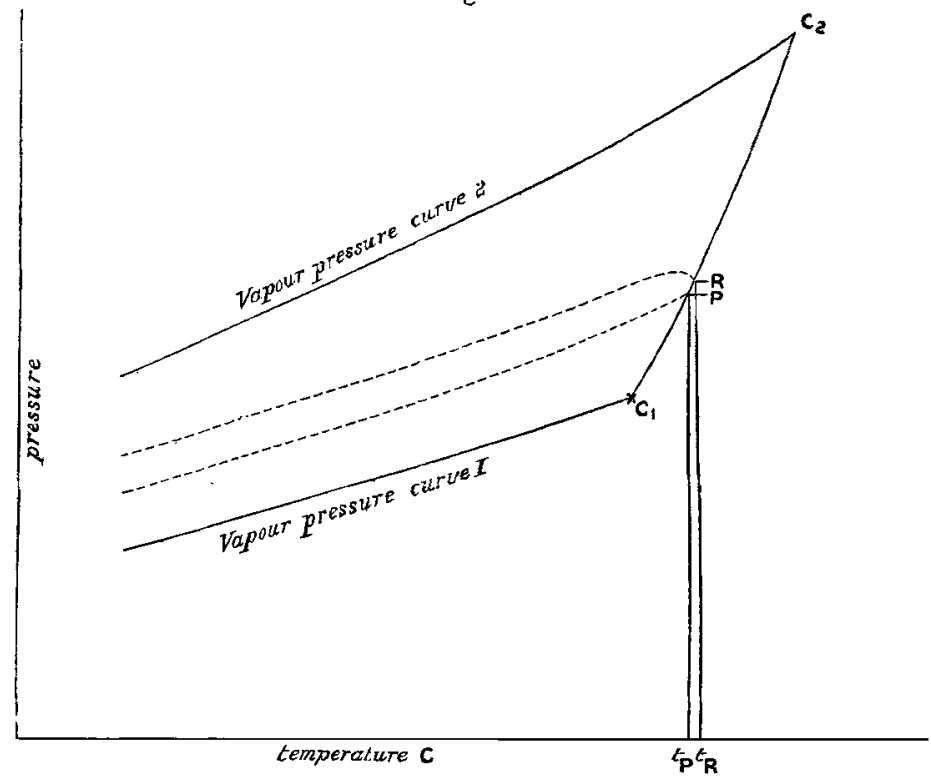

two temperatures $T_{P}$ and $T_{E B}$ the mixture, the border-curve of which is drawn in the figure, must show retrngrade condensation of the 2nd kind (r.c. II.). Even if the curves are more complicated than is supposed in the figure, the curve $\mathrm{C}_{1} \mathrm{C}_{2}$ will nevertheless fulfil the condition at lenst for a part of its course.

7. There is only a small number of combinations of two 
substances which appear to answer the purpose. Substances of low critical temperatures mostly have high critical pressures and high vapour-pressures. When this is not so, the differences are often too small to promise striking results. My attention was at last drawn to ethane, a substance of low critical pressure $( \pm 50 \mathrm{~atm}$.) and a critical temperature of $\pm 34^{\circ}$ C. Combinations of this substance with $\mathrm{HCl}, \mathrm{C}_{2} \mathrm{H}_{2}$, $\overline{\mathrm{N}}_{2} \mathrm{O}$, especially the last, promised good results.

For this combination I expected to find a case such as is represented in fig. 1. It will appear that my expectation has been surpassed in so far as these mixtures happen to offer some interestiug properties which had never been observed and require a more complex representation than fig. 1 . At the same time the phenomenon (r. c. II.), to find which was the starting-point of the investigation, has escaped observation till now.

\section{Preparation of Ethane $\left(\mathrm{C}_{2} \mathrm{H}_{6}\right)$.}

8. The ethane was prepared by electrolysis of a concentrated solution of acetate of sodium. By this process a number of other substances are generated, especially $\mathrm{CO}_{2}, \mathrm{O}_{2}$, $\mathrm{C}_{2} \mathrm{H}_{4}$, and some esters*. The gas was washed in sulphuric acid and a solution of caustic soda, and collected in a big glass bottle (45 litres) again containing a solution of caustic soda. In this manner the $\mathrm{CO}_{2}$ was absorbed entirely. By aid of a mercury compressing machine of Cailletet, which belongs to the set of apparatus of the Leiden Laboratory for experiments at low temperatures, the ethane was liquefied in a small copper vessel. In this operation it passed again through fuming sulphuric acid, caustic potash, and phosphoric anhydride. In order to expel the permanent gases, the liquid ethane was cooled by solid carbonic acid and made to boil. In filling the tubes the gas was afterwards taken from the liquid.

This method of purification at low temperature has been formerly applied by me to $\mathrm{CO}_{2}$ and $\mathrm{CH}_{3} \mathrm{Cl} \dagger$.

\section{Preparation of Nitrous Ocide $\left(\mathrm{N}_{2} \mathrm{O}\right)$.}

9. This substance was taken from a commercial bottle; it was led through high-pressure tubes containing chloride of caleium and eaustic potash and afterwards dried over $\mathrm{P}_{2} \mathrm{O}_{5}$. The purification was conducted as in the former case. During the boiling of the liquid $\mathrm{N}_{2} \mathrm{O}$ the tube could be connected

* Kolbe, Lieb. Ann. lxix. p. 279; Wiedemann, Electricitit, ii. p. 574 .

+ Kuenen, Archives Néerl. xxvi. pp. 356, 359. Olszewski was the first to apply this method of purifying gaseous substances so far as I know. 
with an air-pump, a sort of mercury-valve being interposed in order to prevent air from returning to the liquid.

\section{Preparation of the Mixtures.}

10. The substances thus purified could be mixed in any proportion by means of my mixing apparatus, for the description of which I refer to previous investigations*. At present the whole apparatus consists of glass and copper only: the exhaustion was effected by a mercury air-pump.

\section{Method of the Observations.}

11. For the observations I made use of Ducretet's apparatusf. The glass tubes in which the gisses were to be compressed were connected with the above apparatus by means of ground joints, and repeatedly exhausted and filled with the gases.

12. The temperatures, all of them ranging between $0^{\circ}$ and $40^{\circ} \mathrm{C}$., were obtained by means of a continuous current of water through a tube surrounding the experimental tabes.

13. My stirring apparatus $\neq$, which was continually used during the observations, had been slightly modified. The little piece of iron with its knobs of enamel within the highpressure tubes was the same as before; but the electromagnet, which used to slide over the tube and accordingly within the water-vessel, had been replaced by a larger bobbin sliding over the outside of the water-vessel. In this manner the influence of the temperature of the bobbin upon the temperature of the water, the constancy of which used to be disturbed during the acting of the apparatus, was removed. The bobbin is worked by four Bunsen cells or two accumulators.

\section{Results obtained with Ethane.}

14. In order to test the purity of the substances they were at first investigated separately. The gases appeared still to contain a little impurity : there was a slight increase of pressure during the process of condensation, for the ethane at $20^{\circ}$, 0.56 atmosphere. The amount of impurity of a gas corresponding to a definite increase of pressure at a definite temperature is difficult to decide, and entirely depends upon the substance itself and the admixture. In preparing the gas a second time, the liquid ethane was cooled in liquid ethylene boiling at a low pressure $\left(-110^{\circ}\right.$ C.), itself being connected with an air-pump as in the case of nitrous oxide. The ethane obtained in this manner was found to be a little purer

* Kuenen, l.c. p. $369 . \quad \dagger$ L. c. pp. 357, $366 . \quad \ddagger$ L. c. pp. 372 sqq. 
still : the increase of pressure was $0.43 \mathrm{~atm}$. at the same temperature*.

15. The critical temperature of the gases was determined very carefully: as with the mixtures, a stirring-rod had been put within the tube, and so the determination could be conducted according to the principles explained in the account of my observations with $\mathrm{CO}_{2} \dagger$. The critical temperature for the two samples of ethane amounted to $31^{\circ} .95 \mathrm{C}$. and $32^{\circ} .05 \mathrm{C}$. respectively. This would point to a critical temperature of $\pm 32^{\circ} \cdot 3$ for pure ethane. By admitting a little air $\left(\frac{1}{4}\right.$ to $\frac{1}{2}$ per cent.) into the last tube the increase of pressure at $20^{\circ} \mathrm{C}$. rose to $2.7 \mathrm{~atm}$., $i$. e. more than six times the former value; while the critical temperature had gone down to $31^{\circ} .25 \mathrm{C}$. This would point to $\pm 32^{\circ} \cdot 2 \mathrm{C}$. as the real critical temperature of ethane. The admixture in my ethano seems to lie far below $0 \cdot 1$ per cent.

16. It is not impossible that, in filling the tubes, a little air remains in the gases, because they have to pass through some long tubes connected with joints before entering the experimental tube, and the air has to be expelled by means of exhaustion. I might probably have got a still purer gas by filling the tube more directly, but I preferred to apply exactly the same method which I used in preparing the mixtures, in order to be warranted against mistakes resulting from differences of purity.

17. The critical temperature of ethane as determined by former observers is somewhat higher. Dewar $\ddagger$ gives $35^{\circ} \mathrm{C}$., Olszewski $\$ 34^{\circ}$ C., Haenlen $\|$ from $32^{\circ}$ C. to $40^{\circ} \mathrm{C}$., prohably $34^{\circ} .5 \mathrm{C}$. In his experiments retardation has played an important part, and his gas cannot have been very pure; otherwise one finds a definite critical point, not a critical region as he does. He prepared the gas by the method of Gladstone, Tribe, and Frankland Tा from $\mathrm{C}_{2} \mathrm{H}_{5} \mathrm{I}$. Olszewski obtained ethane from $\mathrm{C}_{2} \mathrm{H}_{5} \mathrm{Zn}$. Both Haenlen and Olszewski purified the gas by cooling and boiling at a low temperature.

I cannot tell what the reason is of this discordance between the values for the critical temperature. Perhaps it has some connexion with the different ways of preparing the gas. I am going to repeat the experiments with ethane prepared

\footnotetext{
* Andrews, in his famous experiments on carbonic acid, observed an increase of pressure of more than two atmospheres in a similar case.

$\dagger$ Kuenen, Kon. Akad. Amsterdam, 29 Oct. 1893, pp. 85-90; Communications, \&c., No. 8, pp. 11, 12.

† Dewar, Phil. Mag. [5] xviii. p. 214.

Olszewski, Bulletin Ac. des Sciences de Cracovie, 1889, p. 27.

II Haenlen, Lieb. Ann. cclxxxii. p. 245.

Gi J. Chem. Soc. xlv. p. 154 ; xlvii. p. 236.
} 
from $\mathrm{C}_{2} \mathrm{H}_{5} \mathrm{I}$. But the difference may be due to the method of determining the critical state as well. In my experiments the retardation is entirely annihilated by carefully stirring the gas, which may have lowered the critical temperature.

\section{Results obtained with Nitrous Oxide.}

18. Similar results were obtained with this gas. The increase of pressure, however, was still less. At $20^{\circ} \mathrm{C}$. it amounted to $0 \cdot 15 \mathrm{~atm}$. $=11 \mathrm{~cm}$. of mercury. The impurity of the gas may be estimated below $0 \cdot 0002$ : for the critical temperature I obtained $35^{\circ} .95$ and $36^{\circ} 05$. The true value will be $36^{\circ} \cdot 1 \mathrm{C}$. probably.

19. Villard, who has prepared pure nitrous oxide by a similar process ${ }^{*}$, fixes the critical temperature of his gas at $38^{\circ} .8 \mathrm{C}$. But this value was obtained by the indirect method of measuring the densities. The liquid surface disappeared below $38^{\circ} \mathrm{C}$., but he does not mention an exact value. This gas must have been very pure, judging from the regular phenomena obtained near the critical point, and the purity of the carbonic acid prepared in the same manner. Villard states that in a U-tabe in which two quantities of liquid $\mathrm{N}_{2} \mathrm{O}$ were separated by a column of mercury, a pressure of a few centimetres sufficed to liquefy one of the portions completely. But this test is not so delicate as the one given above, viz. the entire increase of pressure from the beginning to the end of the liquefaction $\uparrow$.

20. The constancy of my results with the pure substances and the smallness of the admixture left, justify me in accepting an influence of the admixture upon the behaviour of the mixtures of a similar small amount.

* Villard, C. R. cxviii. p. 1096; Journal de Phys. [3] iii. Oct. 1894. In a letter Dr. Villard tells me that his estimation of the critical temperature has been too high. In turning a tube with $\mathrm{N}_{2} \mathrm{O}$ at $36^{\circ} .5 \mathrm{C}$., the liquid surface disappeared and the tube filled itself with a blue mist. Now as stirring comes to the same as repeated turning, it is quite natural that I obtained a value for the critical temperature below $36^{\circ} .5 \mathrm{C}$. I have not noticed the blue mist more than $0^{\circ} .2$ or $0^{\circ} .3$ above $36^{\circ} .0 \mathrm{C}$. At any rate the disagreement between Villard's result and mine has been reduced to a few tenths of a degree. But it appears from Villard's measurements of the densities of $\mathrm{N}_{2} \mathrm{O}$, that the behaviour of this substance near its critical point is less normal, so to speak, than the behaviour of carbonic acid. One feels inclined to ascribe this to the influence of ninute impurities.

$\dagger$ In filling a tube with a gas, which is compressed to a liquid afterwards, one works under unfayourable conditions for obtaining a pure substance compnred to what can be obtained with liquids. The isopentane prepared by Prof. Young (Phil. Mag. [5] xxxriii. 1894, pp. 569-572) is remarkable in respect to purity. Here the increase of pressure appears to have disappeared entirely. Experiments by Battelli and others prove that even a pure liquid is not easily obtained. 
Results obtained with the Mixtures.

21. The number of mixtures investigated was five. The composition ( $x$ parts of ethane in the volume in the gaseous state at one atmosphere) amounted to $0 \cdot 18,0 \cdot 25,0 \cdot 43,0 \cdot 55$, 0.76 respectively. The pressure and volume at the beginning and at the end of the condensation as observed at different temperatures are given in Tables I.-VII. The values of the volumes are only approximate. They are expressed in parts of the volume at $1 \mathrm{~atm}$. and $0^{\circ} \mathrm{C}$. For $\mathrm{N}_{2} \mathrm{O}$ and $\mathrm{C}_{2} \mathrm{H}_{6}$ only one value for the pressures has been given. 'Tables VIII. $-X$. give the volumes for the temperatures $20^{\circ}, 25^{\circ}$, and $26^{\circ}$ C., as determined by graphical interpolation from the values observed.

TABLES I.-VII.

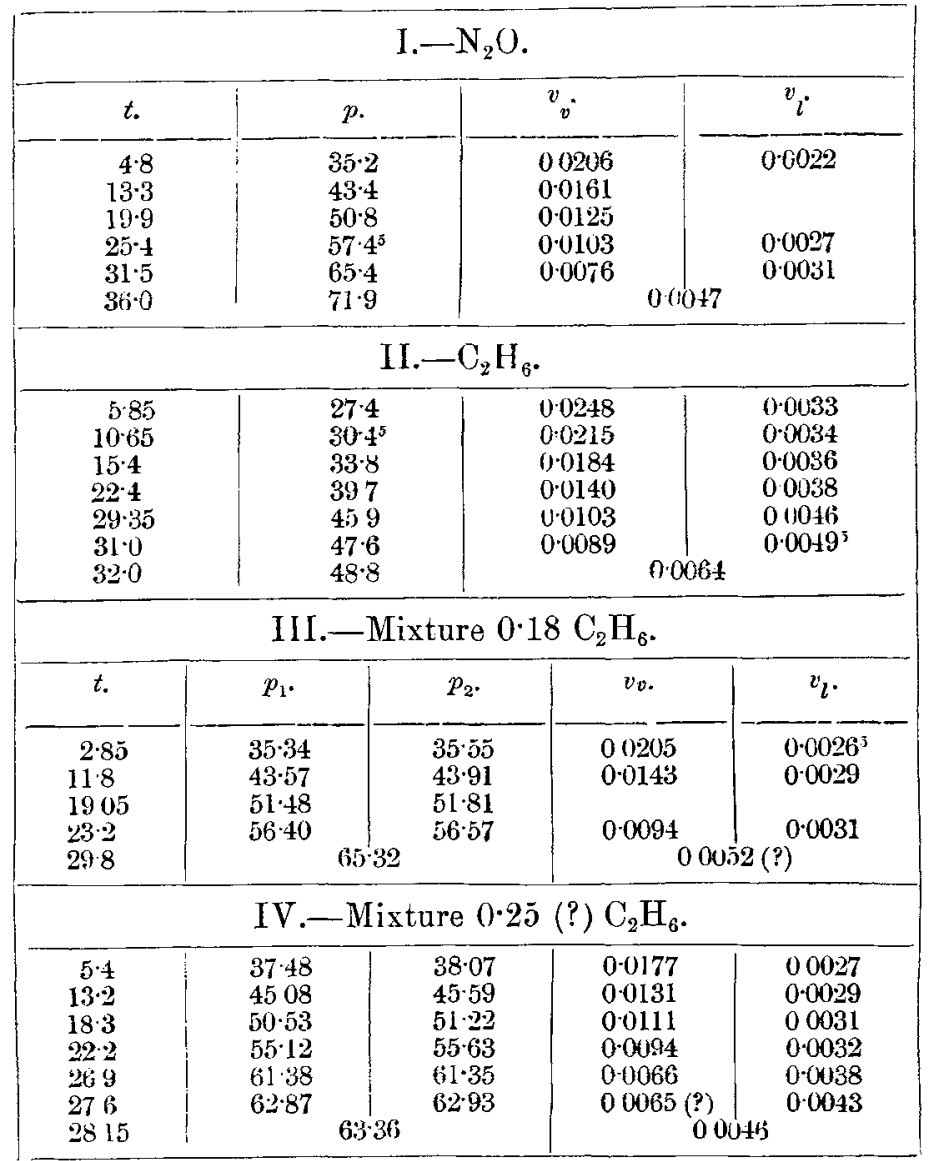


Dr. Kuenen on the Critical Phenomena of

Tables (continued).

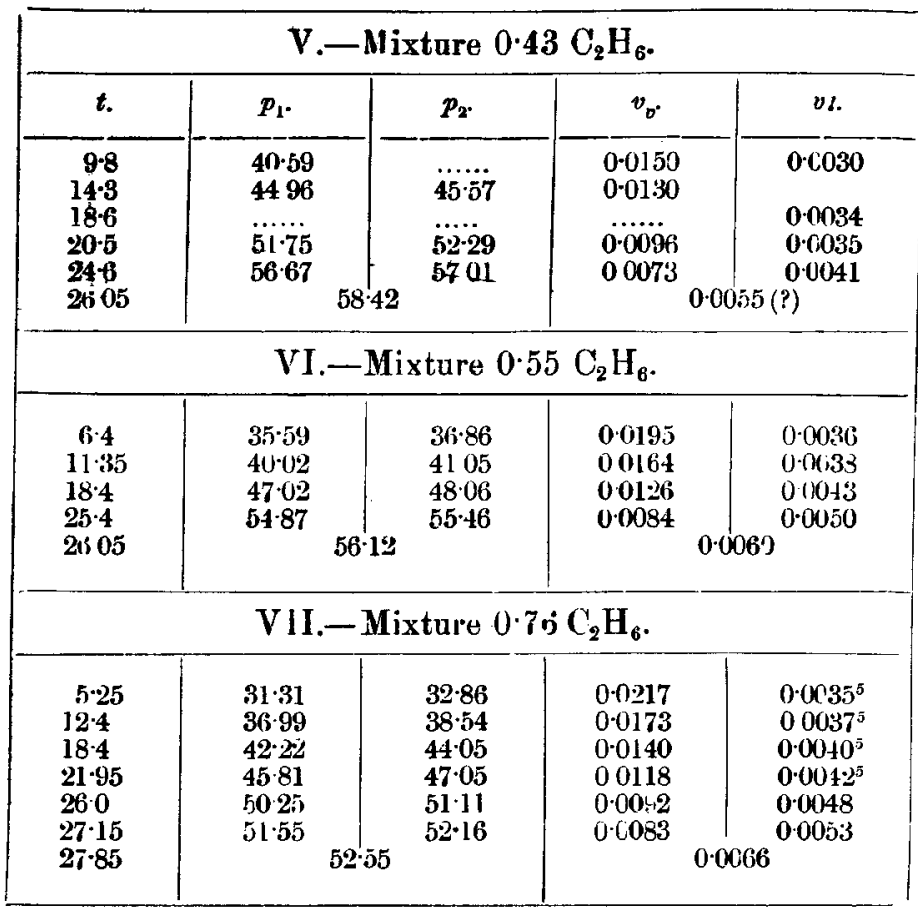

Tables VIII.-X.

\begin{tabular}{|c|c|c|c|c|c|c|}
\hline \multicolumn{7}{|c|}{ VIII.-Volumes at $20^{\circ}$ (fig. 3). } \\
\hline$x=0.0$ & 0.18. & 0.25 . & 0.43 . & $0 \cdot 55$. & $0 \cdot 76$. & 1.0. \\
\hline $\begin{array}{l}0.0125 \\
0: 0025^{5} \\
\end{array}$ & $\begin{array}{r}106 \\
30 \\
\end{array}$ & $\begin{array}{r}102 \\
32 \\
\end{array}$ & $\begin{array}{l}98^{5} \\
35 \\
\end{array}$ & $\begin{array}{r}113 \\
42^{3} \\
\end{array}$ & $\begin{array}{r}130 \\
41^{5} \\
\end{array}$ & $\begin{array}{r}155 \\
37^{5} \\
\end{array}$ \\
\hline \multicolumn{7}{|c|}{ IX.-Volumes at $25^{\circ}$ (fig. 4). } \\
\hline $\begin{array}{l}00104^{s} \\
00026^{s}\end{array}$ & $\begin{array}{l}\mathbf{8 7} \\
\mathbf{3 3}\end{array}$ & $\begin{array}{l}78 \\
35^{5}\end{array}$ & $\begin{array}{l}70^{3} \\
42\end{array}$ & $\begin{array}{l}84^{5} \\
48\end{array}$ & $\begin{array}{l}98^{5} \\
45\end{array}$ & $\begin{array}{r}126 \\
40\end{array}$ \\
\hline \multicolumn{7}{|c|}{ X.-Volumes at $26^{\circ}$ (fig. 5). } \\
\hline $\begin{array}{l}0.0101 \\
0.0027^{5}\end{array}$ & $\begin{array}{l}85^{3} \\
34\end{array}$ & $\begin{array}{l}73 \\
37\end{array}$ & $\begin{array}{l}58^{5} \\
51\end{array}$ & $\begin{array}{l}69 \\
58\end{array}$ & $\begin{array}{l}92 \\
48\end{array}$ & $\begin{array}{l}99 \\
47\end{array}$ \\
\hline
\end{tabular}

The results are laid down in fig. 2 , and figs. 3,4 , and 5 . 
Mixtures of Ethane and Nitrous Oxide.

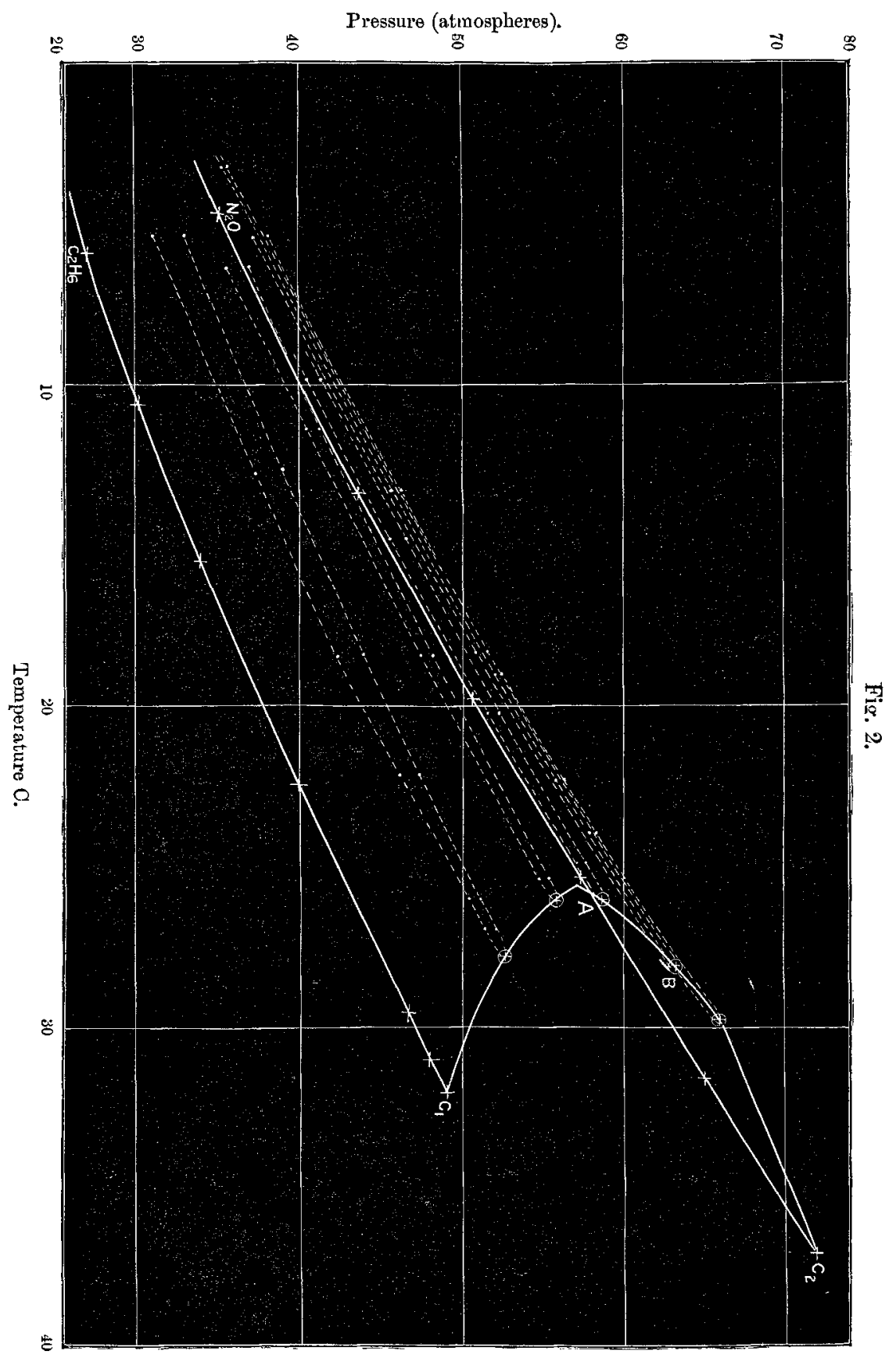


Fig. $3 * t=20^{\circ} \mathrm{C}$.

Composition.

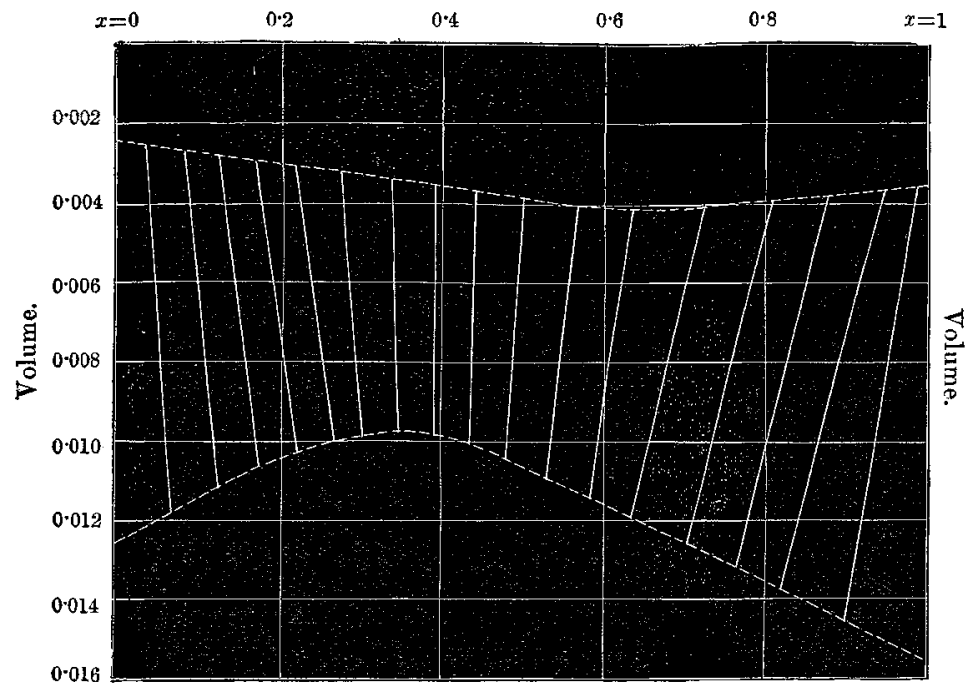

* There is a mistake in fig. 3 in so far as the straight lines near about $x=0.2$ should be parallel to the $\gamma$ axis, as in figs, 4 and 5 .

Fig. 4. $t=25^{\circ} \mathrm{C}$.

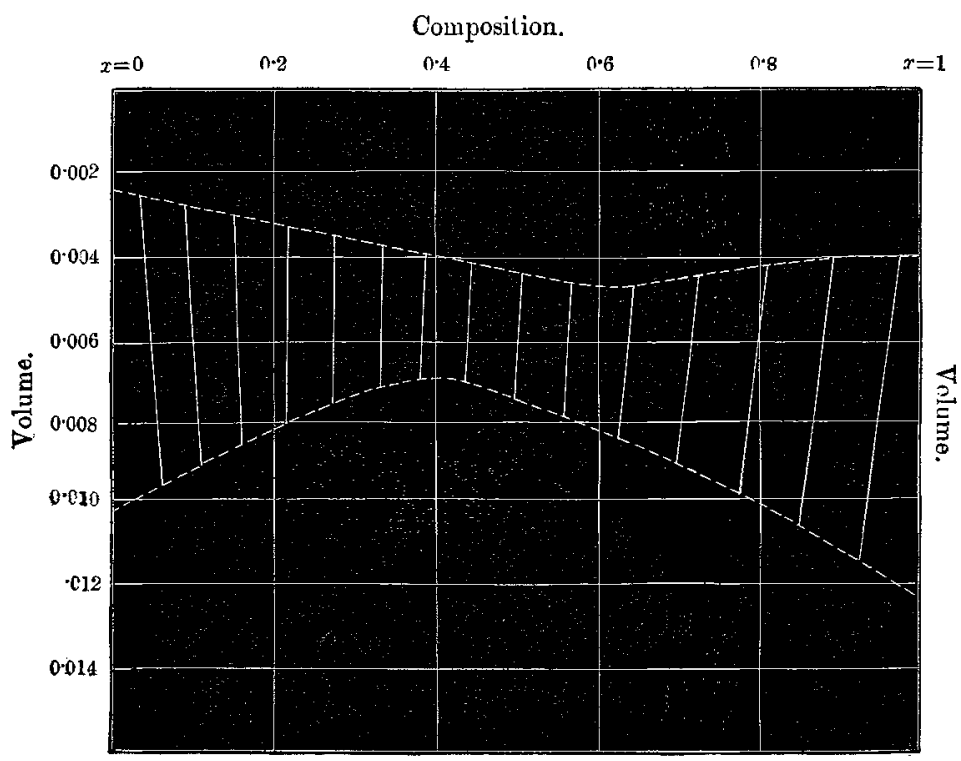


Fig. 5. $t=26^{\circ} \mathrm{C}$.

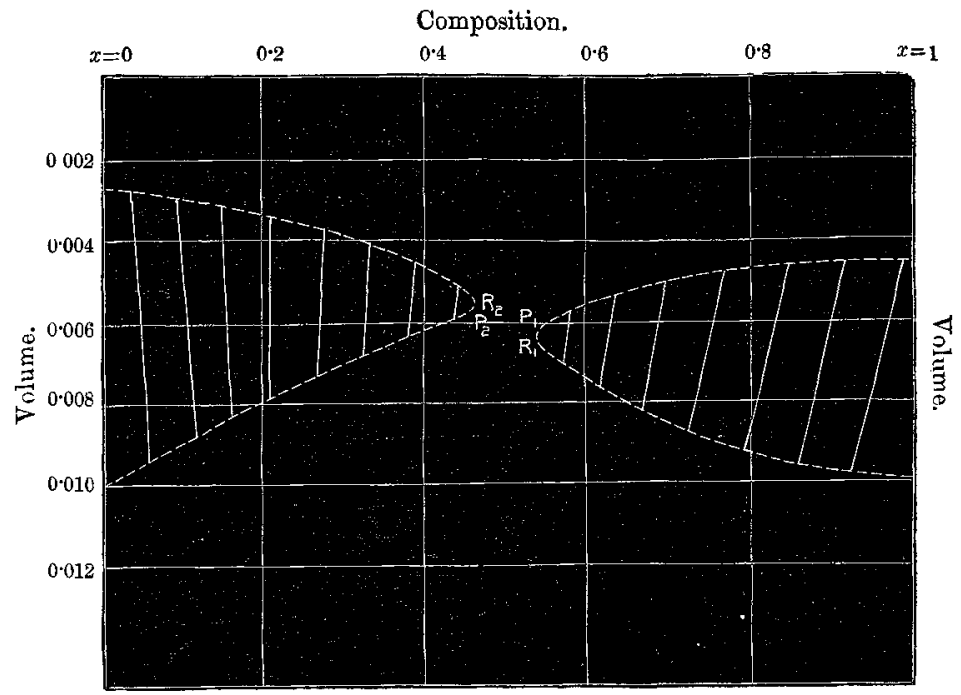

22. The axes of coordination in fig. 2 are $p$ and $t$. This figure may be compared with fig. 1 , which represented the curves as they would have been if the phenomena had been as little complicated as possible.

The curve $\mathrm{C}_{2} \mathrm{H}_{6}-\mathrm{C}_{1}$ is the vapour-pressure curve for ethane, $\mathrm{N}_{2} \mathrm{O}-\mathrm{C}_{2}$ the same for nitrous oxide. $\mathrm{C}_{1}$ and $\mathrm{C}_{2}$ are the critical points. $\mathrm{C}_{1} \mathrm{ABC}_{2}$ is the plaitpoint-curve. The curves of the shape of loops are border-curves for the mixtures.

23. There are two striking differences between fig. 1 and fig. 2.

(1) The critical temperatures for a part of the mixtures lie below those for the components. By adding $\mathrm{C}_{2} \mathrm{H}_{6}\left(32^{\circ}\right)$ to $\mathrm{N}_{2} \mathrm{O}\left(36^{\circ}\right)$, the critical temperature is lowered to a disproportionate extent. For a mixture containing $\pm 0 \cdot 1$ of $\mathrm{C}_{2} \mathrm{H}_{6}$ the critical temperature has gone down as far as to $32^{\circ}$, the c. t. for pure ethane. All mixtures containing more ethane than 0.1 have critical temperatures below $32^{\circ}$. Addition of $\mathrm{N}_{2} \mathrm{O}$ to $\mathrm{C}_{2} \mathrm{H}_{6}$ therefore makes the critical temperature decrease instead of increase. The lowest critical temperature $( \pm 25 \cdot 8)$ belongs to a mixture containing \pm 0.5 of ethane.

A case like this has never been observed till now; van der Waals's theory shows the possibility of the critical temperature lying outside those for the components*.

* There is one instance of a mixture, the critical temperature of which lies above those for the components, observed by Dewar, namely, of $\mathrm{CO}_{2}$ and $\mathrm{C}_{2} \mathrm{H}_{2}$ (Proc. Roy. Soe. of Lond. xxx. p. 543).

Phil. Mag. S. 5. Vol. 40. No. 243. Aug. 1895. 
24. (2.) There is another difference between fig. 1 and fig. 2. The border-curves of the mixtures do not all of them lie between the vapour-pressure curves of $\mathrm{C}_{2} \mathrm{H}_{6}$ and $\mathrm{N}_{2} \mathrm{O}$. Some of them lie above the $\mathrm{N}_{2} \mathrm{O}$ curve. It follows that at every temperature there is a maximum of pressure for one of the mixtures. From the figure it appears that this maximum lies somewhere between the mixtures the composition of which is 0.18 and $0 \cdot 25$, say $\pm 0 \cdot 2$. The bordercurves of the mixtures 0.18 and 0.25 differ only very slightly and in the figure almost coincide. The meaning of this is that the maximum belongs to almost the same mixture at all temperatures represented in the figure. If the mixture for which the pressure is a maximum varied quickly with change of temperature, the border-curves of the mixtures in that neighbourhood would intersect at perceptible angles. If we tried to draw the curve giving the maximum pressure at any temperature, it would lie a very little above the bordercurves for $x=0.18$ and $x=0.25$, and be about parallel to those. This curve we shall call the maximum-curve.

25. There is another remarkable quality of the bordercurves in this region near the maximum, viz. the narrowness of the border-curves, i.e. the very small increase of pressure during the condensation. The value of this increase amounts to $0 \cdot 2-0.3 \mathrm{~atm}$. for the first mixture, which is only a very little more than what still remained in the pure nitrous oxide itself*. We may therefore almost take it equal to zero. This agrees with what follows from the theory of mixtures. In a maximum-point (and also in a minimum-point) the two coexisting phases have the same composition (x) though different volumes $(v)$, and there is no increase of pressure during the condensation. In order to determine the exact value of the maximum, a large number of mixtures lying about $x=0 \cdot 2$ should be investigated : only the small admixture in the components themselves would of course impede the fixing of the maximum-curve.

26. In itself the existence of a maximum (or minimum)

* The increases for the second mixture $(0 \cdot 25)$ are somewhat higher. viz. \pm 06 atm., which must be due to a somewhat larger impurity of that mix ture. Probably the pressures of this mixture are therefore a little too high at the same time. The maximum will therefore be nearer to the first mixture $(0 \cdot 18)$. That is why $I$ have put it equal to $\pm 0 \cdot 20$. On the whole the values for the increase of pressure are a little irregular, which is quite natural considering the difficulty of these observations with mixtures. From the observations one might, perhaps, conclude that the maximum with rise of temperature shifts a little towards the $\mathrm{N}_{2} \mathrm{O}$; but as this seems rather uncertain, $I$ prefer taking it constantly equal to $0 \cdot 20$. 
pressure is not a new phenomenon. Guthrie*, Konowalow $\uparrow$, and others have found the same with different mixtures. Only, so far as I know, a maximum (or minimum) has never been traced up to the critical temperature. In Konowalow's mixtures the maximum appears sometimes to shift with change of temperature, and accordingly probably to disappear below the critical temperature. The above results prove that this need not be the case at all. This fact may be expressed in this manner : the maximum-curve need not reach the vapourpressure curve of one of the substances. In my experiments it reaches the plaitpoint-curve, near $B$.

27. These results will be much better understood by inspecting figs. $3,4,5$. The curves in these figures give the relation between the composition of the mixtures and the volumes at which the condensation begins and at which it ends (vid. $\S 1 s q q$.), and may at the same time be considered as the projection of the connodal curves of the plait in van der Waals's surface upon the $v-x$ plane. The figures belong to the temperatures $20^{\circ}, 25^{\circ}$, and $26^{\circ} \mathrm{C}$. respectively.

28 . If the phenomena were such as would correspond to fig. 1 , the plait with rise of temperature would get narrower near the $\mathrm{C}_{2} \mathrm{H}_{6}$ plane $(x=1)$. At $32^{\circ} \mathrm{C}$. the curve would loose itself from the $v$-axis for $x=1$, whilst forming a plaitpoint there; above $32^{\circ} \mathrm{C}$. it would withdraw towards the $\mathrm{N}_{2} \mathrm{O}$ axis $(x=0)$, where it would disappear at $36^{\circ} \mathrm{C}$. (critical temperature of $\mathrm{N}_{2} \mathrm{O}$ ).

29. However, this is not what really happens. With rise of temperature the plait becomes narrower somewhere near the middle. Consequently, at a temperature far below $32^{\circ} \mathrm{C}$, near $25^{\circ} .8 \mathrm{C}$, , the plait divides into two parts. At that moment two plaitpoints appear $\left(\mathrm{P}_{1}\right.$ and $\left.\mathrm{P}_{2}\right) f$. The two parts into which the plait is divided henceforth withdraw towards $x=0$ and $x=1$ separately. At $32^{\circ} \mathrm{C}$. the right-hand plait disappears at $x=1$. At $36^{\circ} \mathrm{C}$, the left-hand plait disappears in $x=0$. Above $36^{\circ} \mathrm{C}$. there is no plait left : the surface is convexo-convex henceforth, and all its points represent stable phases.

30. A maximum pressure (or minimum) manifests itself in the $v-x$ figure in the position of one of the lines connecting

* Phil. Mag. [5] xriii. p. 510 et sqq.

$\dagger$ Wied. Ann. xiv. p. 34.

$\neq$ In two interesting papers (Wien. Ber. xcviii. pp. 1154-91; Archives Nérl. xxiv. pp. 57-98, 295-368) Prof. Korteweg has derived the geometrical properties of the plaits and plaitpoints. The case occurring here, riz. the formation of two plaitpoints of the same kind at the same time, is discussed on pp. 303-305. 
the pairs of coexisting phases being parallel to the $z$-axis. The lines on both sides of the maximum line will be turned in opposite directions (with a minimum the direction in which the lines turn is the opposite of what it is here). But the angles of the lines are very small in the case of $\mathrm{C}_{2} \mathrm{H}_{6}$ and $\mathrm{N}_{2} \mathrm{O}$. On the right-hand plait the lincs differ more: the increase of pressure is accordingly larger on that side of the surface. In the figure the turning of the lines had to be exaggerated in order to show their direction.

31. The critical phenomena of the mixtures were much simpler than I expected to find them. All the mixtures showed normal condensation up to the critical point, and a difference between plaitpoint temperature and critical temperature could not be determined with any certainty, The probable cause of this disagreement I shall refer to after having deduced more completely the theoretical consequences of the experimental results laid down in fig. 2 , and figs. $3,4,5$ (vid. $\S \S 43-46$ ).

\section{Theoretical Conclusions to be drawn from the Eaprerimental Curves.}

32. A. Maximum-Curre--It may be proved that the bordercurve of a mixture for which the pressure becomes a maximum touches the maximum-curve with both its branches. This is represented in fig. 6 . In every point of the maximum-curve

Fig. 6.

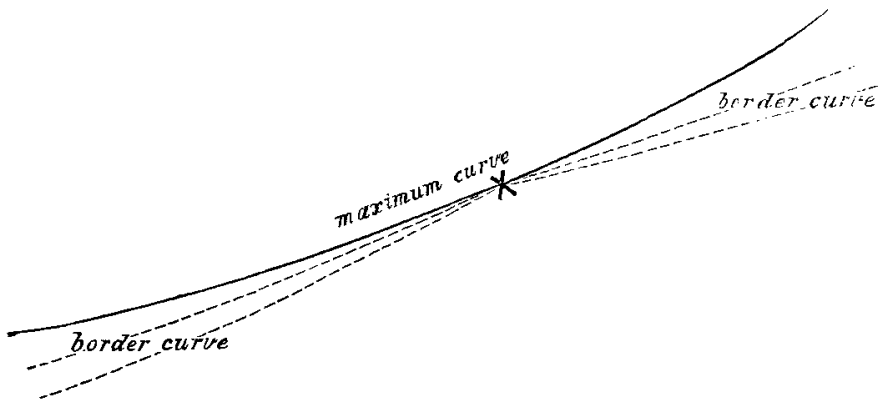

a similar meeting of three curves takes place. If the maximum-mixture does not change much with the temperature (as we found was the case with $\mathrm{C}_{2} \mathrm{H}_{6}$ and $\mathrm{N}_{2} \mathrm{O}$ ), the bordercurve of the maximum mixture must have nearly shrunk to on a curve coineiding with the maximum-curve.

33. Apparently the $p-t$ figure is not at all eonvenient for showing the situation of the border-eurves near the maximum-curve. The border-curves for the mixtures situated on 
both sides near the maximum-mixture cover each other in the figure. In a case like this it is much better to add as a third axis of coordination the $x$-axis, and to draw the $p$ - $t$ curves for the mixtures each in its own plane. The curves together in this manner form the $p-t-x$-surface. Sections of the $p$-t-x-surface perpendicular to the $t$-axis again give curves having the shape of loops ( $p-x$-curves), which may be considered as an extension of Konowalow's curves*: he only gives the upper branches of the $p-x$-curves. A complete $p-x-$ curve is given by Prof. van der Waals in his treatise $\uparrow$.

34. The maximum-curve meets the plaitpoint-curve in $B$. Fig. 7 shows the manner in which the three curves (the

Fig. 7.

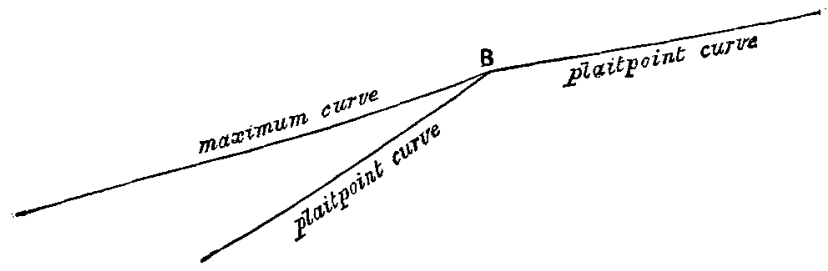

maximum-curve and the two branches of the plaitpointcurve) meet in B. It will have to be decided theoretically whether, perhaps, the plaitpoint curre has no singular point in $B$, in which case the maximum-curve would touch it in $B$.

35. B. Critical Phenomena.-The plaitpoint-curve (fig. 2) consists of three parts, being situated between both the critical Fig. 8.

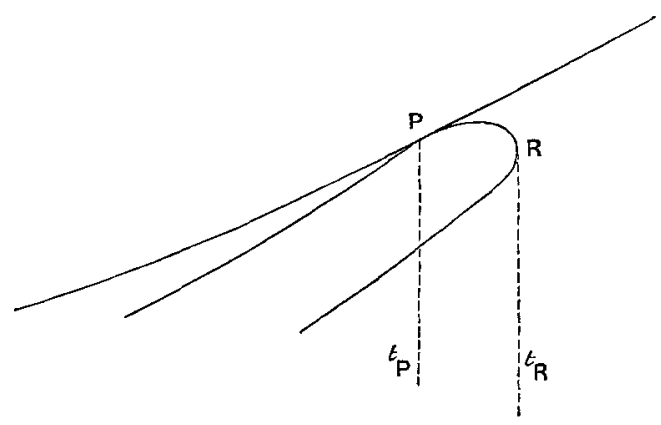

points $\mathrm{C}_{1}$ and $\mathrm{C}_{2}$, and separated by the two points $A$ and $B$. $A$ is the meeting-point of two branches of the plaitpoint-

* Wied. Ann. xiv. p. 34.

$\dagger$ Arch. Néerl. xxiv. p. 21. 
curve, where the critical temperature is lowest*. In B the maximum-curve meets the plaitpoint-curve.

36 . In the part $\mathrm{C}_{2} \mathrm{~B}$ the relative position of plaitpointcurve and border-curves is like fig. 8. $\mathrm{P}$ lies in the direction we called beyond $R$, and the border-curves touch the plaitpoint-curve on its right side. The mixtures baving their plaitpoint between $\mathrm{C}_{2}$ and $\mathrm{B}$, i.e. containing less than $0.2 \mathrm{C}_{2} \mathrm{H}_{6}$, therefore must have retrograde condensation of the first kind (r.c. I.) between the temperatures $t_{\mathrm{P}}$ and $t_{\mathrm{R}}$.

37. In the part $\mathrm{C}_{1} \mathrm{~A}$ the curves are situated as in fig. 9 . The border-curves lie on the left-hand side, but the plait-

Fig. 9.

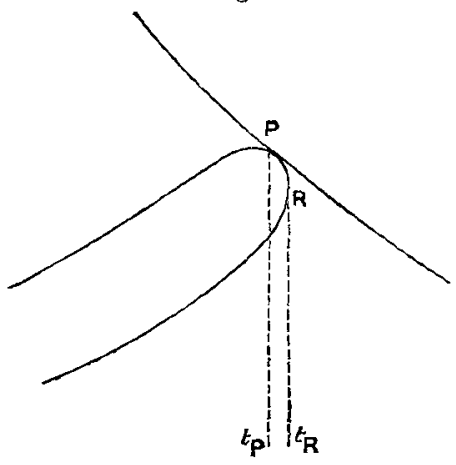

point-curve falls. $\mathbf{P}$ lies beyond $\mathrm{R}$. The mixtures having their plaitpoint here, i.e. containing more than $0.5 \quad \mathrm{C}_{2} \mathrm{H}_{6}$, must also have r.c. I. between $t_{\mathrm{P}}$ and $t_{\mathrm{R}}$.

Fig. 10.

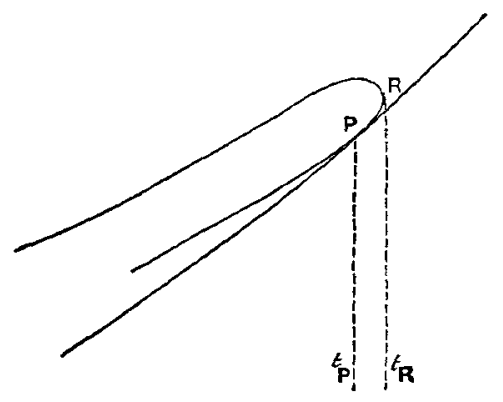

38. The part BA, however, fulfils the condition for the existence of r.c. II., as is shown in fig. 10 (vid. §6). The plait-

* The existence of a singular point in A was suggested to me by the experimental curves (fig. 2, vid. \$42). Professor van der Waals, to whom I showed my experimental results, told me that he has theoretical 
point-curve rises, and the border-curves lie on its left side. $\mathbf{R}$ lies beyond $\mathrm{P}$. In this region lie the mixtures the composition of which is between 0.2 and $0.5 \mathrm{C}_{2} \mathrm{H}_{6}$.

In consequence of the complexity of the curves as compared to fig. 1 , the region of r.c. II. is a great deal smaller than it would have been according to fig. 1 (BA instead of $\mathrm{C}_{1} \mathrm{C}_{2}$ ). It is easy to see that this was the only thing which could happen : r.c. II. could not disappear entirely.

39. These rather strange conclusions are entirely made clear by figs. 3, 4, 5. These represent exactly the same phenomena, only in a different manner. If $\mathrm{P}$ lies above $\mathrm{R}$ we have r.c. I. ; if it lies below $R$, we have r.c. II. At first, after the dividing of the plait, the plaitpoints $\mathrm{P}_{1}$ and $\mathrm{P}_{2}$ lie on opposite sides of $R_{1}$ and $R_{2}$ in the two plaits. This corresponds to the existence of r.c. I. below $A$, and r.c. II. above $A$ in fig. 2. While with rise of temperature the plait $P_{2} R_{2}$ shrinks together, $R_{2}$ approaches the maximum-line. $P_{2}$ approaches $R_{2}$ at the same time, and at the moment that the maximum reaches the end of the plait, $P_{2}$ and $R_{2}$ coincide. At that moment there is no retrograde condensation. The nixture $x=0.2$ behaves at its critical point like a pure substance. $\mathrm{P}_{2}$, however, now continues to move upwards, and henceforth lies a little above $R_{2}$. That explains the existence of r.c. I. between $\mathrm{B}$ and $\mathrm{C}_{2}$. If there had not been a maximum, r.c. II. would have existed all the way from $\mathrm{A}$ to $\mathrm{C}_{2}$.

40. The critical phenomena near the point where the plait divides into its two branches $(t=25 \cdot 8, p=57 \cdot 7 \mathrm{~atm}$.) are of a rather complex nature. This will be understood by the contemplation of fig. 11, where the two branches of the connodal curve at the moment of parting have been drawn on a much larger scale.

Let us consider the condensation of the mixtures $x_{1}$ and $x_{2}$ separately. It will be seen (vid. $\S 1$ ) that the mixture $x_{1}$ in 1 begins to show a liquid phase which increases, decreases, and disappears in 2 (r.c. I.). Then, in 3, the liquid appears again, and in 4 the whole mixture will be liquid (normal condensation). Mixture $x_{2}$ liquefies in $1:$ the liquefaction is at an end in 2 (normal condensation): in 3 a vapour phase appears which disappears in 4 (r.c. II.).

reasons for believing that the plaitpoint-curve is continuous during its whole course, so that neither A nor B wonld be singular points. The conclusions drawn in $\S \S 40-42$ and figures 11 and 12 entirely depend upon the existence of a singular point in $\mathrm{A}$. There is, however, no connexion between those and the rest of this paper. Professor van der. Waals will publish his results ere long. 
41. Quite close to this temperature (below and above it) similar complicated phenomena will exist. A little above

Fig. 11.

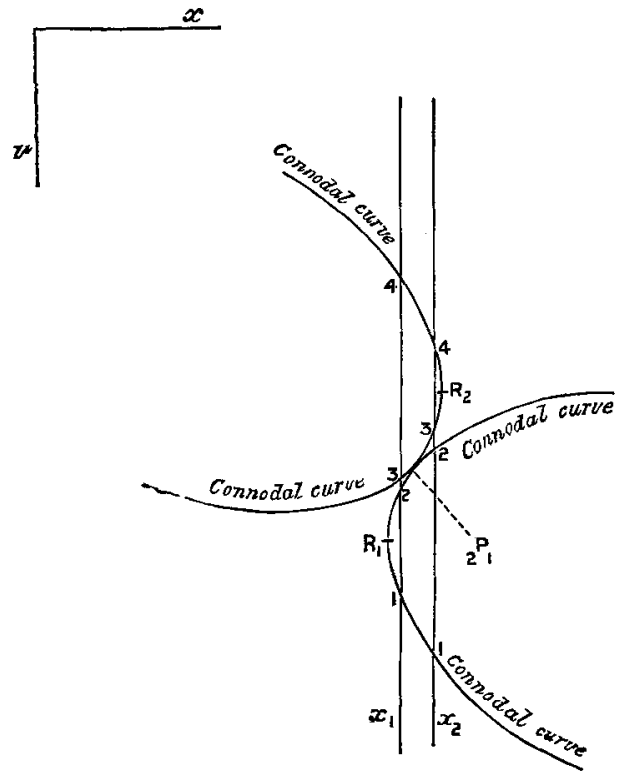

25.8 there are even some mixtures which show first r.c. I. and then r.c. II. successively with compression. But as soon as the plaits have moved so far that there is no $x$-line cutting both plaits, the critical phenomena become the ordinary phenomena for a mixture (r.c. I. or II.).

42. The $p$-t-curves in the neighbourhood of $\mathrm{A}$ have a more complicated character, corresponding to the behaviour of the plait (fig. 12). The two branches of the experimental plaitpoint-curve meet in a singular point. The border-curves show a doubling, which disappears at a small distance from A. A fuller explanation of the.figure seems hardly necessary. For clearness' sake only two border-curves have been drawn in the figure on an exaggerated scale.

43. How is it that in my experiments the mixtures did not show any of those critical phenomena partly of a so complicated nature, and almost behaved like pure substances near their critical points? $(\$ 31)$. The reason lies at hand : I have pointed out the smallness of the increase of pressure, $i . e$. the approximate parallelism of the straight lines in fig. $3(\$ 30)$, and the exceeding narrowness of the loops (border-curves) in fig. 2 (\$25). Accordingly, as will be noticed in both figs. 2 and 5, the two critical points $P$ and $R$ lie close together, and 
the distance between the temperatures of the plaitpoint and the critical point of contact ( $t_{\mathrm{P}}$ and $t_{\mathrm{R}}$ ), for the same mixture,

Fig. 12.

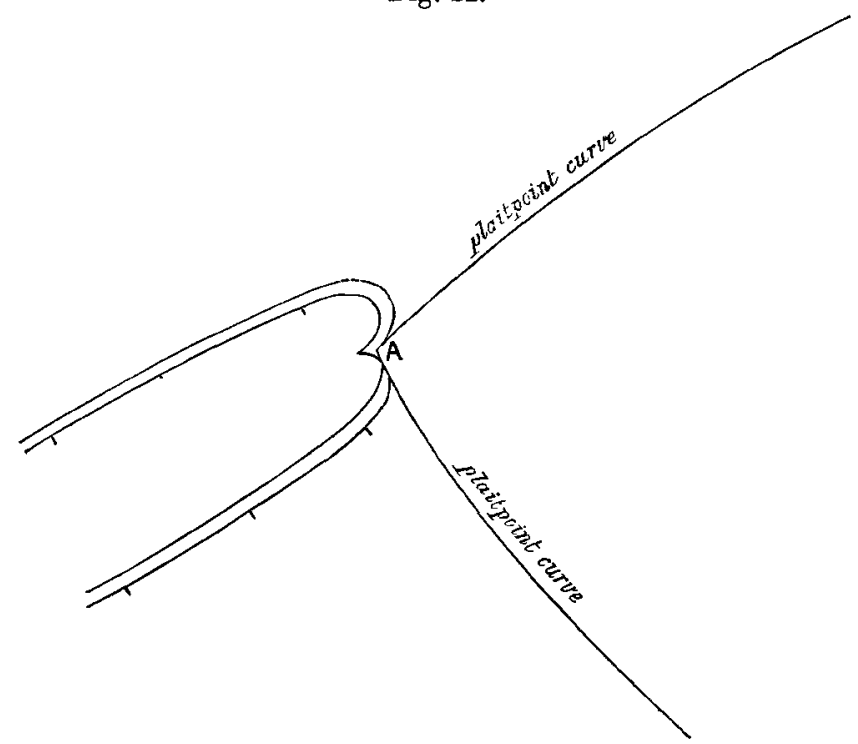

can be very small only. An estimation from the original figure 2 gives $+0^{\circ} \cdot 1 \mathrm{C}$. at the utmost for the distance between $t_{\mathrm{P}}$ and $t_{\mathrm{R}}$, and in some parts of the plaitpoint-curve-for instance near B-much less still. Now in order to fix so small a difference the temperature ought to be perfectly constant for a long while, which was not the case in my water-vessel. There were slow changes, which of course did not prevent the determination of the critical point taken as a whole. I think this circumstance may be taken as a sufficient explanation of the disagreement between theory and experiments.

44. However, there is another cause which must have cooperated in confusing the pure phenomena, viz. the influence of gravitation. It was Gouy* who, in the case of pure substances, first pointed out the importance of this factor near the critical point, where the substances become so highly compressible. In the case of mixtures the influence of gravitation is not of a quite simple nature. The result is this : near the plaitpoint there is a small region in which the complete process of the condensation is confused ; namely in this manner, that with compression at a certain moment the liquid surface between the phases disappears at some distance from

* Compt. Rend. cxv. p.720, cxvi. p. 1289; cf. Kuenen, 'Communications, etc.' No. 8 , p. 10 . 
the ends of the tube. In this manner the process of retrograde condensation is cut off halfway; and if the distance between the two critical temperatures is very small, the phenomenon may perhaps disappear entirely* This snggests the use of horizontal, or at least nearly horizontal, tubes for experiments on the critical phenomena.

45. Now in this region, where gravitation plays an important part, the stirring of the substance cannot be of any avail ; on the contrary, the equilibrium, which is rery much influenced by gravitation, is spoilt rather by mixing together the different layers. So in this region the only thing we can do is, to wait a long time, and Gouy's experiments with an almost pure substance show that "long" means "days" here ; and of course that would be no use nnless the temperature and the volume could be kept absolutely constant, which is practically impossible.

46. Though the special critical phenomena predicted by means of van der Waals's theory have escaped observation so far, there is no reason to doubt their reality or to see any contradiction between them and my experimental results, I believe.

47. Some of the results arrived at in this investigation may be enumerated here once more :-

1. The mixtures of $\mathrm{C}_{2} \mathrm{H}_{6}$ and $\mathrm{N}_{2} \mathrm{O}$ containing more than 0.1 of $\mathrm{C}_{2} \mathrm{H}_{6}$ have critical temperatures lying beneath those of the substances $(\$ 23)$.

2. The pressures of the mixtures lie partly above those of $\mathrm{N}_{2} \mathrm{O}$, and accordingly show a maximum situated near $0 \cdot 2$ $\mathrm{C}_{2} \mathrm{H}_{6}(\$ 24)$.

3. The maximum does not disappear with increase of temperature, but remains up to the critical region: the maximum-curve reaches the plaitpoint-curve $(\$ 26)$.

4. The mixtures ranging between 0.2 and $0.5 \mathrm{C}_{2} \mathrm{H}_{6}$ have r.c. II., the rest r.c. I.

I intend now to investigate mixtures of acetylene and carbonic acid, a group of which according to Dewart has critical temperatures lying above those of the components. If I should be able to confirm this result, I shall treat that combination in the same manner experimentally and theoretically as $\mathrm{I}$ have done the combination of $\mathrm{C}_{2} \mathrm{H}_{6}$ and $\mathrm{HN}_{2} \mathrm{O}$ in this paper.

The experiments described in this paper have been carried out in the Physical Laboratory at Leiden, to the Director of which, Professor Kamerlingh Onnes, I am indebted for continuous and invaluable advice and help.

* Kuenen, V'erslagen kon. Akad. Amsterdam, 25 Mei, 1895.

† Proc. Roy. Soc. of Lond. xxx. p. 543. 